\title{
Data de desponte apical e intensidade luminosa no crescimento e qualidade de crisântemo de vaso
}

\author{
Gabriel P Garde; Moises A Muniz; Rogério G Pêgo; José Antonio S Grossi
}

UFV-Depto. Fitotecnia, Av. P.H. Rolfs, s/no, 36571-000 Viçosa-MG; pradoufv@yahoo.com.br; mmuniz76@hotmail.com; engagropego@ yahoo.com.br; jgrossi@ufv.br

\section{RESUMO}

O desponte e a aplicação de dias longos são técnicas culturais imprescindíveis à produção de crisântemo, porem pouco se sabe como estes fatores interferem na qualidade das plantas. Assim o objetivo deste trabalho foi avaliar o efeito da data do desponte apical e diferentes intensidades luminosas como "quebra de noite" no crescimento e qualidade de crisântemo de vaso, cultivar Giovani. $\mathrm{O}$ experimento foi realizado em blocos casualizados, em esquema de parcela subdividida, em que as parcelas constituíram as intensidades luminosas $(157,26 ; 66,46 ; 18,73 ; 7,66$ e 3,8 lux) utilizando lâmpadas incandescentes de $100 \mathrm{~W}$ dispostas a um metro de altura dos vasos. As subparcelas constituíram as datas do desponte apical $(15,17,19$ e 21 dias após o estaqueamento, DAE), sendo que as plantas permaneceram sob dias longos até aos 21 DAE. No ápice do florescimento foram avaliadas a altura, diâmetro médio de parte aérea do vaso, número de hastes por vaso, número de nós por haste, comprimento do $3^{\circ}$ e $4^{\circ}$ entrenós, número de inflorescências, massa seca de caule, folha, inflorescência e total da parte aérea. O desponte realizado aos 15 DAE com intensidade de 157 lux resultou em maior número e massa de inflorescências, maior altura, número de nós e melhor qualidade de vaso.

Palavras-chave: Dendranthema grandiflora, fotoperíodo, florescimento, poda.

\begin{abstract}
Date of pinching and different light intensities on growth and quality of potted chrysanthemum

The pinching and application of long days cultivation are techniques essential to the production of chrysanthemum, however little is known about how these factors affect the quality of the plants. Thus the aim of this study was to evaluate the effect of the date of apical pinching and different light intensities as "night break" in the growth and quality of potted chrysanthemum, cultivar Giovani. The experiment was carried out in a randomized block design with split plots, in which the plots were the light intensities (157.26; 66.46; $18.73 ; 7.66$ and 3.8 lux) using incandescent $100 \mathrm{~W}$ lamps, one meter above the pots. The split dates of apical cut were performed 15, 17, 19 and 21 days after staking, (DAE), whereas plants remained under long days until $21 \mathrm{DAE}$. At the peak of flowering we assessed the plant height, diameter of aboveground part of the plants, number of stems per pot, number of nodes per stem, length of $3^{\text {rd }}$ and $4^{\text {th }}$ internodes, number of inflorescences, dry mass of stem, of leaf, of inflorescence and of total aboveground part. The pinching done at $15 \mathrm{DAE}$ with intensity of 157 lux resulted in greater number and inflorescence mass, greater height, number of nodes and better quality of the plants.
\end{abstract}

Keywords: Dendranthema grandiflora, photoperiod, flowering, pinching.

\section{(Recebido para publicação em 9 de agosto de 2012; aceito em 4 de novembro de 2013) (Received on August 9, 2012; accepted on November 4, 2013)}

\begin{abstract}
A produção brasileira de flores e plantas ornamentais vem crescendo anualmente e já se consolida como um importante setor do agronegócio brasileiro. Somente nos cinco primeiros meses do ano de 2011, as exportações brasileiras de flores e plantas ornamentais atingiram US\$ 7,6 milhões (Junqueira \& Peetz, 2011).

O crisântemo (Dendranthema grandiflora), cultivado em vaso é uma das plantas mais populares no Brasil devido à diversidade de cores e beleza de suas inflorescências. A produção brasileira em vaso apresenta rápido crescimento e consiste de uma excelente alternativa de investimento na pequena propriedade agrícola, pois de-
\end{abstract}

manda áreas pequenas, apresenta ciclo de produção curto, alto rendimento por unidade de área, resposta fotoperiódica precisa e grande diversidade de formas e cores nas diferentes cultivares (Brum et al., 2007).

O crisântemo é classificado como planta sensível ao fotoperíodo e tem o florescimento induzido naturalmente sob fotoperíodo crítico de 14,5 horas. As plantas devem receber luminosidade de, no mínimo, 108 lux no nível das folhas. Essa intensidade luminosa não tem o objetivo de promover crescimento nem fotossíntese, mas atuar apenas sobre o controle fotoperiódico da planta (David \& Rossi, 2010). A técnica de "quebra de noite" ou "noite interrompida", por sua vez, visa o uso de iluminação suplementar a fim de realizar o controle fotoperiódico. A utilização de intensidades menores que as recomendadas para o controle fotoperiódico pode determinar a qualidade de vaso. Se o controle não for efetivo, pode resultar em menor biomassa formada no período vegetativo e, consequentemente, menor número de flores por planta (Barbosa, 2003). Entretanto, alguns produtores relatam que quanto maior a intensidade luminosa melhor é a qualidade dos vasos, utilizando intensidades maiores (300 a 800 lux).

Outra importante técnica frequentemente utilizada no cultivo de crisântemo em vaso é o desponte apical das mudas, 
visando aumentar o número de hastes florais por planta e, consequentemente, aumentando o número de flores e a qualidade final de vaso. $\mathrm{O}$ desponte apical objetiva quebrar a dominância apical e possibilitar o desenvolvimento de brotações laterais que contribuem para a produção de hastes com maior número de flores (Barbosa, 2003). Na maioria dos cultivos, a desponta apical em crisântemo de vaso é feita entre 10 e 21 DAE, dependendo do produtor, da cultivar, sem que haja comprovação cientifica de qual a melhor data para o desponte.

A busca de informações sobre a data de desponte e a intensidade luminosa na produção de crisântemo em vaso é fundamental para maior produtividade e qualidade. Assim, o objetivo foi avaliar o efeito da data do desponte apical e diferentes intensidades luminosas no crescimento e qualidade de crisântemo de vaso.

\section{MATERIAL E MÉTODOS}

O experimento foi conduzido em casa de vegetação do Setor de Floricultura do Departamento de Fitotecnia da UFV em Viçosa-MG $\left(20^{\circ} 45^{\prime} \mathrm{S}\right.$, $42^{\circ} 52^{\prime} \mathrm{O}$, altitude $690 \mathrm{~m}$ ), no período de 25 de março a 08 de junho de 2011 com a cultivar de crisântemo de vaso Giovani, grupo mini margarida, de inflorescências com coloração branca, com tempo de reação de 8 semanas, cedidas pela empresa BrasilFlor. A escolha dessa cultivar foi devido à sua grande aceitação pelo mercado consumidor.

$\mathrm{O}$ delineamento experimental foi em blocos casualizado, em esquema de parcelas subdivididas. As parcelas constituíram as intensidades luminosas (157,26; 66,46; 18,73; 7,66 e 3,8 lux), e as subparcelas, as datas de desponte (15, 17,19 e 21 dias após estaqueamento, DAE), com três repetições.

Foram plantadas cinco estacas apicais em cada vaso de polietileno com capacidade de $1,1 \mathrm{~L}$ ( $\left.\mathrm{n}^{\circ} 14\right)$, que representou uma unidade experimental. Os vasos foram preenchidos com substrato comercial, composto por casca de pinus, turfa e vermiculita, cuja densidade foi de $200 \mathrm{~kg} / \mathrm{m}^{3}$, capacidade de retenção de água de $130 \%(\mathrm{p} / \mathrm{p})$, umidade de $60 \%$ (p/p), $\mathrm{pH}$ de 5,8 e condutividade elétrica de $0,5 \mathrm{mS} / \mathrm{cm}$. Após o plantio, os vasos foram levados para câmara de nebulização com freqüência de irrigação de seis segundos a cada 20 minutos, durante os primeiros 21 dias, visando favorecer o processo de enraizamento.

Após o desponte, realizado em função dos tratamentos $(15,17,19$ e 21 dias após o estaqueamento ou plantio), as plantas foram mantidas sob dia longo até aos 21 dias, sendo em seguida levadas para o dia curto até o final do ciclo. As diferentes intensidades luminosas foram obtidas pelo distanciamento horizontal dos tratamentos da fonte luminosa a zero, um, dois, três e quatro metros. Sendo realizado das 22 às $2 \mathrm{~h}$ pelo fornecimento de iluminação artificial com lâmpada incandescente de 100 W localizada a um metro de altura.

A irrigação localizada foi realizada de forma automatizada com gotejadores que forneceram $80 \mathrm{~mL}$ por vaso três vezes ao dia, a partir do $21^{\circ}$ dia após estaqueamento. A fertirrigação foi feita manualmente fornecendo $100 \mathrm{~mL}$ de solução nutritiva por vaso, conforme Muniz et al. (2009), três vezes na semana, em dias alternados à irrigação. Durante o ciclo de cultivo, as temperaturas máximas, mínimas e a umidade relativa foram registradas com auxílio de dataLogger modelo HT500. Foi feito o monitoramento de pragas e doenças durante o experimento, mas apenas foi necessária a aplicação de inseticida piretróide, com dose de $30 \mathrm{~mL} / 100 \mathrm{~L}$, inseticida para controle de pulgão.

As variáveis altura, diâmetro médio de parte aérea de vaso, número de hastes por vaso, número de nós por haste, comprimento do $3^{\circ}$ e $4^{\circ}$ entrenós, número de inflorescências, massas seca de caule, folha, inflorescência e total da parte aérea foram analisadas quando os vasos apresentavam 50\% de inflorescências abertas. Considera-se inflorescência aberta quando a primeira fileira de lígulas da inflorescência está perpendicular à haste floral. A qualidade dos vasos foi avaliada segundo o critério de qualidade do Veilling Holambra (2011).

Os dados obtidos foram submetidos à análise de variância e à regressão polinomial. $\mathrm{Na}$ análise de regressão foram testados os efeitos linear, quadrático do modelo polinomial, $\mathrm{Y}=\mathrm{a}+$ $\mathrm{bx}+\mathrm{b}_{1} \mathrm{x}^{2}$, sendo selecionada aquela de efeito significativo pelo teste $\mathrm{F}$ a $5 \%$ de probabilidade de significado biológico e de maior soma de quadrado, ou seja, maior $\mathrm{R}^{2}$.

\section{RESULTADOS E DISCUSSÃO}

A temperatura no interior do ambiente protegido alcançou valor médio

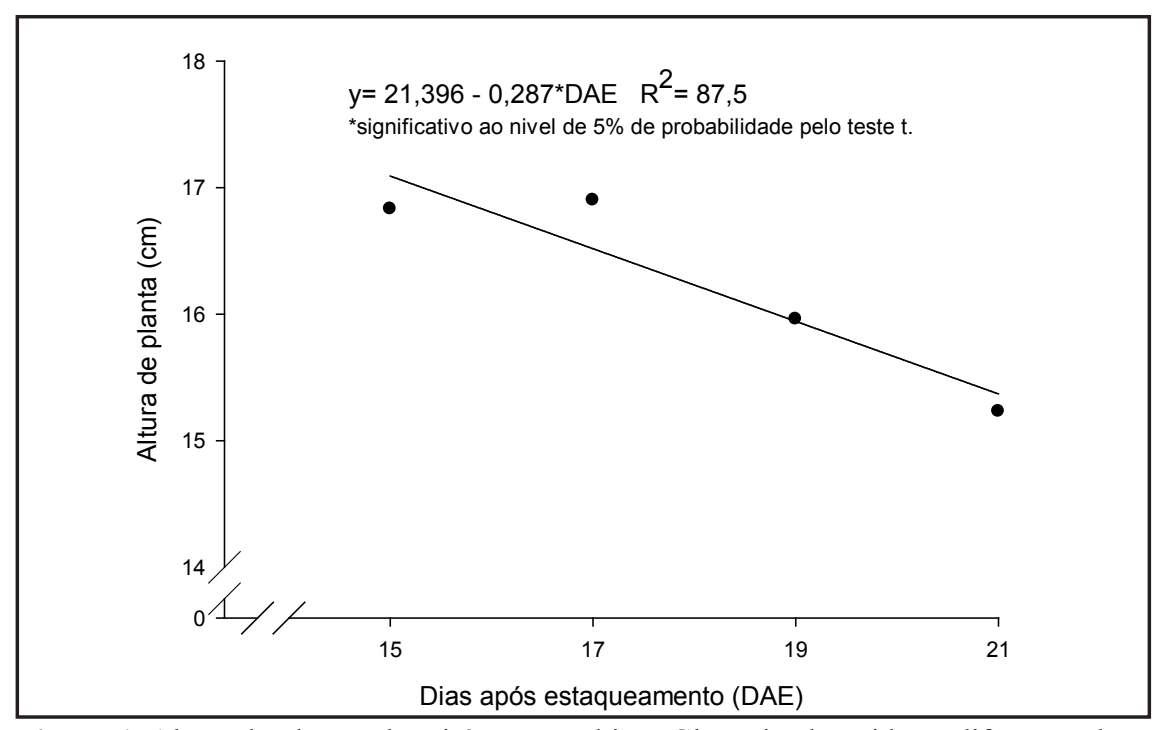

Figura 1. Altura de plantas de crisântemo cultivar Giovani submetidas a diferentes datas de desponte apical (plant height of chrysanthemum cultivar Giovani submitted to different times of pinching). Viçosa, UFV, 2012. 

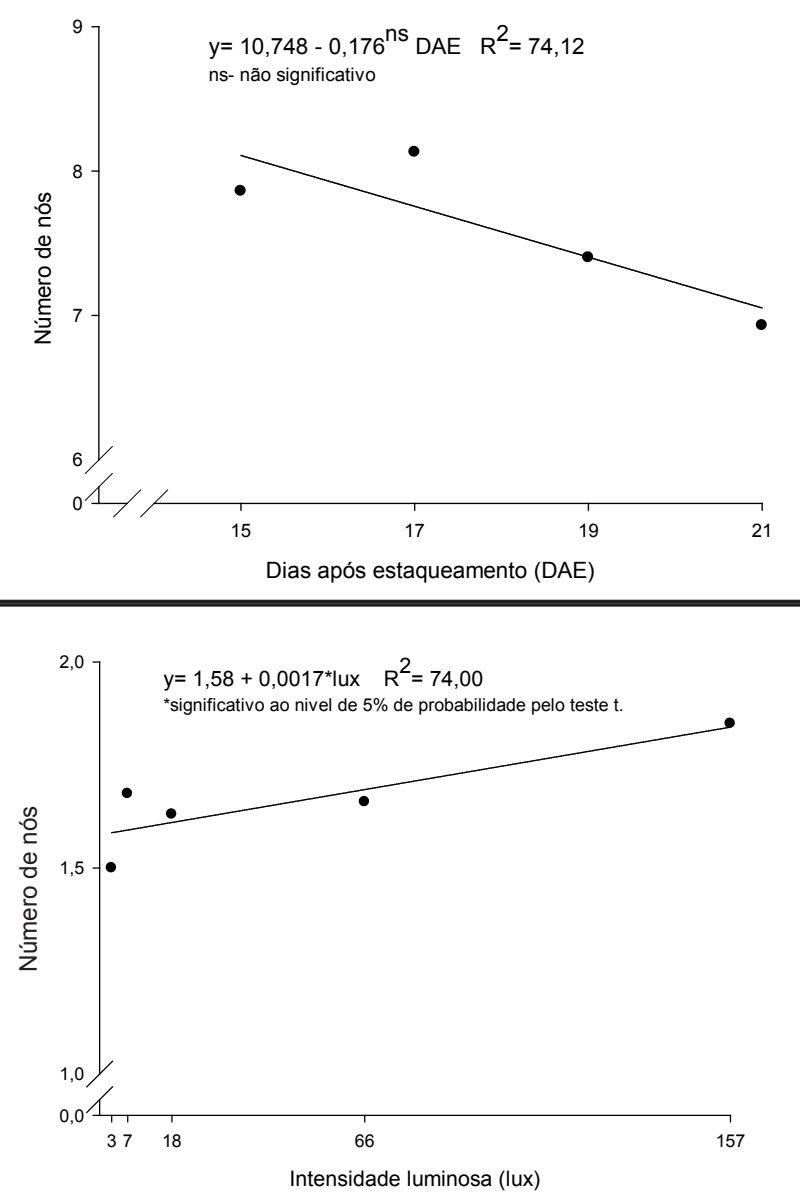

B

Figura 2. Número de nós/haste de plantas de crisântemo cultivar Giovani submetidas a diferentes datas de desponte apical (A) e intensidades luminosas (B) (number of nodes per stem of chrysanthemum plants, cultivar Giovani submitted to different dates of pinching and light intensity). Viçosa, UFV, 2012.

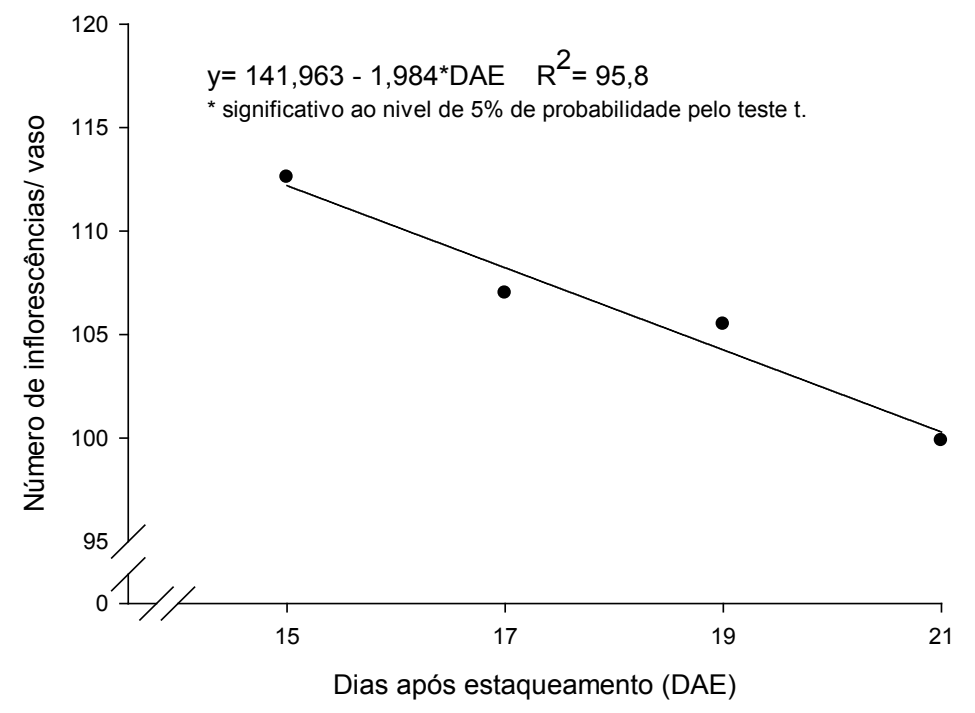

Figura 3. Número de inflorescências/vaso de plantas de crisântemo cultivar Giovani submetidas a diferentes datas de desponte apical (number of inflorescences per pot of chrysanthemum plants, cultivar Giovani submitted to different dates of pinching). Viçosa, UFV, 2012. diurno e noturno de $24,18^{\circ} \mathrm{C}$ e $16,13^{\circ} \mathrm{C}$, respectivamente, enquanto a umidade relativa do ar foi em média $70,28 \%$ e $86,15 \%$ para o período diurno e noturno, respectivamente. Segundo Barbosa (2003), o cultivo comercial de crisântemo deve ser realizado em locais onde a temperatura diurna seja de 23 a $25^{\circ} \mathrm{C}$ e a noturna, em torno de $18^{\circ} \mathrm{C}$. Streck (2004), trabalhando com a resposta do crisântemo em função da temperatura, observou que temperaturas entre $22 \mathrm{e}$ $35^{\circ} \mathrm{C}$ são razoáveis para o desenvolvimento das plantas. Comparando a temperatura e umidade observadas no experimento, com as faixas descritas, observa-se que estas variáveis climáticas não foram fatores limitantes no crescimento e desenvolvimento da cultura.

O diâmetro de parte aérea de vaso, número de hastes por vaso e comprimento do $3^{\circ}$ e $4^{\circ}$ entrenós não foram influenciados pela intensidade luminosa e data de desponte, apresentando médias de 24,$74 ; 18,8 ; 2,1$ e 1,67 cm respectivamente.

A altura foi influenciada apenas pela data de desponte, sendo decrescente a partir dos 15 dias com altura estimada em $17 \mathrm{~cm}$ (Figura 1). Valores superiores $(20$ a $30 \mathrm{~cm})$ foram observados por Muniz et al. (2009) que executaram o desponte aos 18 dias em cultivares de crisântemo do grupo decorativo. A menor altura no presente experimento é devida ao menor crescimento vegetativo do grupo mini-margarida em relação ao grupo decorativo.

Quanto ao número de nós, houve influência dos tratamentos, mas a interação entre eles não foi significativa. A data de desponte 15 DAE (Figura 2A) e a intensidade luminosa de 157 lux (Figura 2B) proporcionaram o maior número de nós. Ao contrário disso, não houve diferença significativa para o comprimento de entrenós. Brum et al. (2007), trabalhando com desponte em crisântemo multiflora, observaram aumento no número de nós com incremento das horas de exposição ao dia longo, fato este semelhante ao ocorrido neste experimento. Já Bellé et al. (2007), trabalhando com crisântemo de corte, cultivar 'Gompier Chá', atribuíram o incremento em altura de hastes não tratadas com $\mathrm{GA}_{3}$ ao aumento significativo 


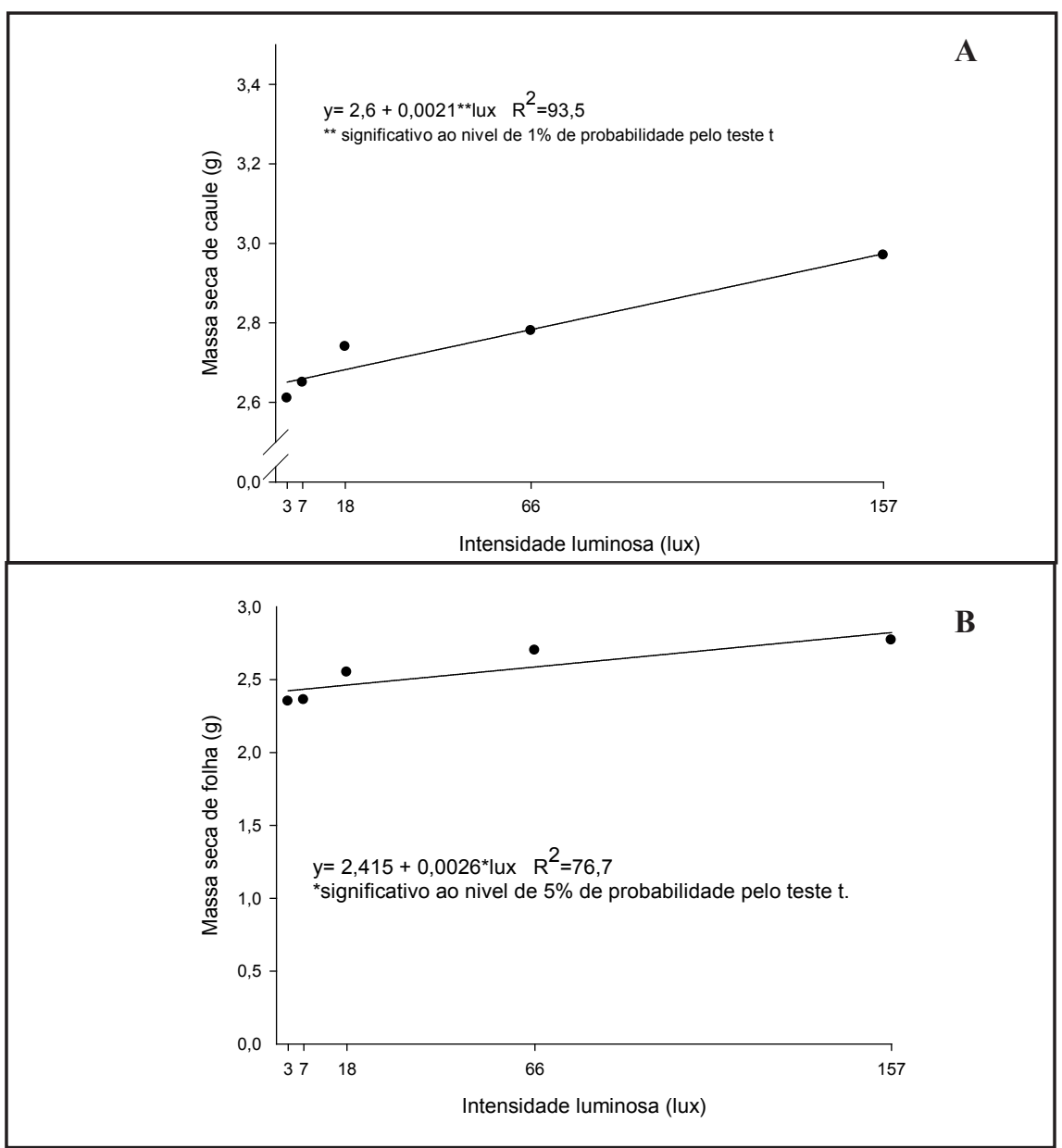

Figura 4. Massa seca de caule (A) e folha (B) de plantas de crisântemo, cultivar Giovani submetidas a diferentes intensidades luminosas (stalk and leaf dry mass of chrysanthemum plants, cultivar Giovani submitted to different light intensities). Viçosa, UFV, 2012.

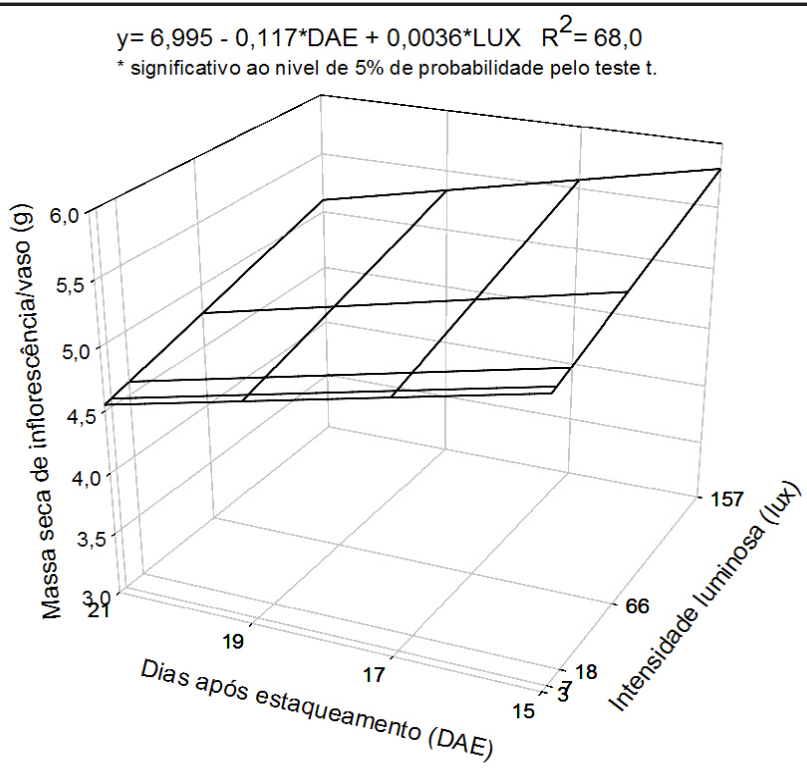

Figura 5. Massa seca de inflorescências de plantas de crisântemo cultivar Giovani submetidas a diferentes intensidades luminosas e datas de desponte (inflorescence dry mass of chrysanthemum plants, cultivar Giovani submitted to diferente light intensities and dates of pinching). Viçosa, UFV, 2012. do número de nós por planta.

O número de inflorescências por vaso é considerado um dos parâmetros mais importante na conformação do vaso, pois quanto maior o número de flores por vaso, melhor a formação do buquê e, consequentemente, melhor qualidade final de vaso. No presente experimento, o número de inflorescências foi influenciado apenas pelos dias após desponta, sendo o valor médio obtido aos 15 DAE com 22,52 inflorescências planta $^{-1}$ (Figura 3), similar ao encontrado por Petry et al. (1999). Esses autores verificaram que a cultivar de crisântemo de vaso 'Pappilon' (tipo margarida) produziu 25,3 inflorescências planta ${ }^{-1}$. Valores semelhantes foram também observados por Ferreira (2009) que, realizando o desponte aos $21 \mathrm{DAE}$, observou que as cultivares 'Eugene Yellow' e 'Durban' apresentaram 16,5 e 23,6 inflorescências planta $^{-1}$ respectivamente.

$\mathrm{O}$ aumento da altura, do número de nós e de inflorescências por planta é devido ao desponte, realizado aos $15 \mathrm{DAE}$, propiciando a manutenção das plantas por maior período em condições de crescimento vegetativo após o desponte apical, ou seja, maior tempo de exposição ao dia longo. Este fato favorece o crescimento dos brotos laterais em relação às demais épocas de desponte, uma vez que, os dias longos são usados para manter o crescimento vegetativo das plantas. Estes resultados são semelhantes aos observados por Nxumalo \& Wahome, (2010) que, com o aumento da exposição de plantas de crisântemo de corte ao dia longo, verificaram aumento na altura das plantas.

A massa seca do caule e da folha foram influenciadas apenas pela intensidade luminosa, sendo as maiores médias obtidas com 157 lux: 2,97 e 2,77, respectivamente (Figura 4). No entanto, a massa seca total não foi influenciada pelos tratamentos. Ao contrário disso, a massa seca das inflorescências foi influenciada pela data de desponte e intensidade luminosa. A maior massa seca de inflorescência estimada, foi obtida com data de desponte de 15 DAE e intensidade luminosa de 157 lux (Figura 5).

É conhecido que plantas de crisântemo mantidas sob dia longo vegetam por 
mais tempo, produzindo maior numero de nós e consequentemente maior numero de gemas que irão ser induzidas ao florescimento porque em cada nó há uma gema. Dessa forma, quanto maior o numero de gemas floríferas induzidas, maior será o numero de inflorescências e, consequentemente, maior massa seca de inflorescências. Barbosa (2003) recomenda para o controle do florescimento de crisântemo, a aplicação de dias longos, utilizando lâmpadas de 100 watts distribuídas de forma a se ter uma intensidade luminosa de 90-110 lux. Entretanto, no presente experimento, a intensidade de 157 lux propiciou o maior crescimento de plantas e qualidade de vaso. Embora intensidades menores de lux (7,0 e 4,0 lux) tenham atingido o ponto de colheita aos 66 DAE, diferente das demais (76 DAE), entretanto a qualidade das plantas, conforme Veilling Holambra (2011), foi inferior àquela obtida com 157 lux. Considerando os dados apresentados para a cultivar estudada, concluiu-se que a realização do desponte aos 15 DAE com intensidade luminosa de 157 lux proporcionou maior altura, número de nós, número e massa seca de inflorescências e, consequentemente, melhor qualidade de vaso. Assim, quanto mais precoce a data do desponte e maior a intensidade luminosa após o desponte, melhor será a qualidade final das plantas de crisântemo.

\section{REFERÊNCIAS}

BARBOSA JG. 2003. Crisântemos: Produção de mudas, cultivo para corte de flor, cultivo em vaso, cultivo hidropônico. Aprenda Fácil. Viçosa, 231p.

BELLÉ RA; ROGGIA S; KUSS RCR. 2007. Gibberellic acid and short day interrupted in cut chrysanthemum (Dendranthema grandiflora, Tzvelev., "Gompier Chá"). Ciência Rural 37: 357-362.

BRUM B; SANTOS VJ; RODRIGUES MA; BELLÉ RA; LOPES SJ. 2007. Crescimento, duração do ciclo e produção de inflorescências de crisântemo multiflora sob diferentes números de despontes e tamanhos de vasos. Ciência Rural 37: 682-689.

DAVID E; ROSSI LA. 2010. Diferentes tecnologias de iluminação para produção de mudas de crisântemo. Revista Brasileira de Engenharia Agrícola e Ambiental 14: 261-266.

FERREIRA LDB. 2009. Crop characteristics and nutrients accumulation in the chrysanthemum cultivars for pot in Goiania-GO. Goiás: UFG.132p (Tese doutorado).

JUNQUEIRA AH; PEETZ MS. Boletim de análise conjuntural do Mercado de flores e plantas ornamentais no Brasil. IBRAFLOR. Disponível em: http://www.ibraflor.com/ publicacoes/vw.php?cod=161. Acessado em 18 de agosto de 2011.

MUNIZ M.A; BARBOSA JG; GROSSI JAS; ORBES MY; SÁ PG. 2009. Produção e qualidade de crisântemo de vaso fertirrigados com diferentes relações de nitrato/amônio. Bioscience Journal 25: 75-82.

NXUMALO SS; WAHOME PK. 2010. Effects of application of short-days at different periods of the day on growth and flowering in chrysanthemum (Dendranthema grandiflorum). Journal of Agriculture \& Social Sciences 6: 39-42.

PETRY C; BELEDELI L; ARAUJO EM. 1999. Respostas de cultivares de crisântemo ao manejo de iluminação e ao número de plantas por vaso. Revista Brasileira de Horticultura Ornamental 5: 121-132.

STRECK NA. 2004. A temperature response function for development of the chrysanthemum (Chrysanthemum $x$ morifolium Ramat.). Ciência Rural 34: 49-54.

VEILLING HOLAMBRA. 2011. Critérios de padrão e qualidade. Disponível em: http:// www.veiling.com.br/qualidade. Acessado em 18 de agosto de 2011. 